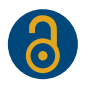

Author affiliations and support information (if applicable) appear at the end of this article.

Published at jco.org on June 29, 2018. Clinical trial information: NCT01506492. Corresponding author: Gary Rodin, MD, Department of Supportive Care, Princess Margaret Cancer Centre, University Health Network, 610 University Ave, 16-724, Toronto, Ontario M5G 2M9, Canada; e-mail: gary.rodin@uhn.ca.

(C) 2018 by American Society of Clinical Oncology. Licensed under the Creative Commons Attribution 4.0 License.

\section{(c) (i)}

0732-183X/18/3623w-2422w/\$20.00

\title{
Managing Cancer and Living Meaningfully (CALM): A Randomized Controlled Trial of a Psychological Intervention for Patients With Advanced Cancer
}

Gary Rodin, Christopher Lo, Anne Rydall, Joanna Shnall, Carmine Malfitano, Aubrey Chiu, Tania Panday, Sarah Watt, Ekaterina An, Rinat Nissim, Madeline Li, Camilla Zimmermann, and Sarah Hales

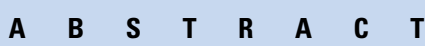

\section{Purpose}

Individuals with advanced cancer experience substantial distress in response to disease burden and impending mortality. Managing Cancer And Living Meaningfully (CALM) is a novel, brief, manualized psychotherapeutic intervention intended to treat and prevent depression and end-of-life distress in patients with advanced cancer. We conducted a randomized controlled trial to compare CALM with usual care (UC) in this population.

\section{Methods}

Patients with advanced cancer were recruited from outpatient oncology clinics at a comprehensive cancer center into an unblinded randomized controlled trial. Permuted block randomization stratified by Patient Health Questionnaire-9 depression score allocated participants to CALM plus UC or to UC alone. Assessments of depressive symptoms (primary outcome), death-related distress, and other secondary outcomes were conducted at baseline, 3 months (primary end point), and 6 months (trial end point). Analyses were by intention to treat. Analysis of covariance was used to test for outcome differences between groups at follow-up, controlling for baseline. Mixed-model results are reported.

\section{Results}

Participants ( $n=305$ ) were recruited between February 3, 2012, and March 4, 2016, and randomly assigned to CALM $(n=151)$ or UC $(n=154)$. CALM participants reported less-severe depressive symptoms than UC participants at 3 months $(\Delta=1.09 ; P=.04$; Cohen's $d=0.23 ; 95 \% \mathrm{Cl}, 0.04$ to $2.13)$ and at 6 months $(\Delta=1.29 ; P=.02 ; d=0.29 ; 95 \% \mathrm{Cl}, 0.24$ to 2.35$)$. Significant findings for greater end-of-life preparation at 6 months also favored CALM versus UC. No adverse effects were identified.

\section{Conclusion}

Findings suggest that CALM is an effective intervention that provides a systematic approach to alleviating depressive symptoms in patients with advanced cancer and addresses the predictable challenges these patients face.

J Clin Oncol 36:2422-2432. (C) 2018 by American Society of Clinical Oncology. Licensed under the Creative Commons Attribution 4.0 License: http://creativecommons.org/licenses/by/4.0/

\section{INTRODUCTION}

The diagnosis of advanced cancer may trigger enormous distress and the challenge of living meaningfully in the face of progressive disease. Individuals in this situation face the burden of physical suffering, the threat of dependency and impending mortality, and the difficulty of making treatment decisions that have life-and-death implications while navigating a complex health care system. ${ }^{1}$ Early palliative care for such individuals has been shown to produce better outcomes, ${ }^{2-4}$ but the psychological dimensions of such care are much less systematized than those focused on symptom control and advance care planning.

Ground-breaking research on supportiveexpressive therapy has demonstrated positive effects on psychological outcomes in women with metastatic breast cancer. ${ }^{5-7}$ More recently, three systematic reviews of randomized controlled trials (RCTs) confirmed that psychotherapy is effective in treating depressive states in individuals with advanced cancer, despite methodological limitations in most studies. ${ }^{8-10}$ Both Dignity Therapy, ${ }^{11}$ a legacy-building intervention for those near the 
Table 1. Comparison of CALM Intervention and UC

\begin{tabular}{|c|c|c|}
\hline Variable & CALM Intervention & UC \\
\hline Oncology clinics and distress screening & $\begin{array}{l}\text { Oncology clinic-based treatment and follow-up; routine } \\
\text { distress screening in clinics, with distress screening } \\
\text { results provided to oncology staff during clinic visit }{ }^{27}\end{array}$ & $\begin{array}{l}\text { Oncology clinic-based treatment and follow-up; routine } \\
\text { distress screening in clinics, with distress screening } \\
\text { results provided to oncology staff during clinic visit }{ }^{27}\end{array}$ \\
\hline $\begin{array}{l}\text { Receipt of supportive care/psychosocial } \\
\text { oncology care }\end{array}$ & Yes (all participants) & $\begin{array}{l}\text { Oncology clinic staff may refer on the basis of clinical } \\
\text { judgment, patient request, or distress screening }\end{array}$ \\
\hline $\begin{array}{l}\text { Supportive care/psychosocial oncology } \\
\text { clinicians }\end{array}$ & $\begin{array}{l}\text { Psychosocial clinicians trained in CALM* (eg, master's } \\
\text { degree-level social workers and psychiatrists in the } \\
\text { present trial; may also be delivered by a wide range of } \\
\text { other trained cancer care providers eg, psychologists, } \\
\text { psychiatry residents, clinical nurse specialists, etc.). }{ }^{17} \\
\text { additional social work consultation for practical/ } \\
\text { instrumental assistance, and/or psychiatry consultation } \\
\text { for monitoring or pharmacotherapy upon } \\
\text { recommendation of CALM therapist }\end{array}$ & $\begin{array}{l}\text { Psychosocial clinicians (eg, master's degree-level social } \\
\text { workers, psychiatrists, psychologists, psychiatry } \\
\text { residents) } \\
\text { Approximately } 33 \% \text { of patients with advanced cancer at } \\
\text { our center are referred for supportive care, } 66 \% \text { of } \\
\text { whom see social work for brief supportive interactions } \\
\text { and practical/instrumental assistance without } \\
\text { psychotherapy } \\
\text { Of the } 33 \% \text { seen by psychiatry or psychology, care } \\
\text { involves diagnostic consultation; treatment with } \\
\text { pharmacology, if needed; and/or brief, nonstandardized } \\
\text { psychotherapy that is integrative in nature and may } \\
\text { draw on other techniques, depending on need and } \\
\text { clinician training }\end{array}$ \\
\hline Clinician training* & $\begin{array}{l}\text { Clinicians attend a 2-day intensive CALM training } \\
\text { workshop, followed by competent completion of at } \\
\text { least two cases, as determined by the developers of } \\
\text { CALM (G.R. and S.H.) as well as weekly clinical case } \\
\text { supervision }\end{array}$ & Nonstandardized \\
\hline Semistructured psychotherapy & $\begin{array}{l}\text { Three to six CALM sessions on average over } 3 \text { to } 6 \\
\text { months (at least one session per month during first } 3 \\
\text { months) individualized and tailored to patient's needs in } \\
\text { both content and process }\end{array}$ & $\begin{array}{l}\text { Less than } 10 \% \text { of patients with advanced cancer referred } \\
\text { receive any form of structured psychotherapy }\end{array}$ \\
\hline Modality & $\begin{array}{l}\text { Individual; primary caregiver (spouse or family member) } \\
\text { invited to participate in one or more CALM sessions as } \\
\text { deemed appropriate by patient and therapist }\end{array}$ & Nonstandardized \\
\hline Manualized psychotherapy & $\begin{array}{l}\text { Yes (all participants), with attention to four broad domains: } \\
\text { symptom management and communication with health } \\
\text { care providers, changes in self and relations with close } \\
\text { others, spiritual well-being and the sense of meaning } \\
\text { and purpose, and mortality and future-oriented } \\
\text { concerns }\end{array}$ & None \\
\hline Length of sessions & Sessions on average 45 to 60 minutes & Nonstandardized \\
\hline $\begin{array}{l}\text { Psychiatric monitoring and/or } \\
\text { pharmacotherapy }\end{array}$ & $\begin{array}{l}\text { Yes, when clinically indicated; upon referral of treating } \\
\text { oncologist or as recommended by CALM therapist }\end{array}$ & $\begin{array}{l}\text { Yes, when clinically indicated; upon referral of treating } \\
\text { oncologist }\end{array}$ \\
\hline Palliative care & $\begin{array}{l}\text { Multidisciplinary palliative care }{ }^{28,29} \text { upon referral of } \\
\text { treating oncologist or as recommended by CALM } \\
\text { therapist }\end{array}$ & $\begin{array}{l}\text { Multidisciplinary palliative care }{ }^{28,29} \text { upon referral of } \\
\text { treating oncologist }\end{array}$ \\
\hline
\end{tabular}

very end of life, and Meaning-Centered Psychotherapy, ${ }^{12,13}$ a group or individual intervention that promotes a sense of meaning and purpose in patients with advanced cancer, have been shown to be effective in a variety of outcomes. ${ }^{13-15}$

We have developed a novel, brief, tailored supportiveexpressive psychotherapeutic intervention, referred to as Managing Cancer And Living Meaningfully (CALM) for patients with advanced cancer and a prognosis of at least 1 year. ${ }^{16}$ On the basis of relational, attachment, and existential theory, CALM provides a therapeutic relationship and reflective space, with attention to the following domains: symptom management and communication with health care providers, changes in self and relations with close others, spiritual well-being and the sense of meaning and purpose, and mortality and future-oriented concerns. ${ }^{17}$ The CALM domains are addressed for each patient in a tailored, individualized manner that allows for variation in the number of sessions and time spent on each domain on the basis of the patient's needs and health status. CALM can be delivered by a wide range of trained psychosocial oncology clinicians and cancer care providers. ${ }^{17}$
In pilot trials with patients with advanced cancer, we demonstrated that CALM is feasible and found evidence of improvement in depression, death anxiety, spiritual well-being, and attachment security. ${ }^{18,19}$ In qualitative interviews, participants reported that CALM provides a "safe place" that helped them to "be seen as a whole person by the medical system," "grow as a person," and "be able to handle death in a peaceful way." ${ }^{20} \mathrm{We}$ now report quantitative findings from an RCT of CALM. The primary outcome was the severity of depressive symptoms, which was selected because of evidence that depression is a final common pathway of distress in this population. ${ }^{21}$ The primary end point of 3 months was chosen a priori to minimize the effects of attrition as a result of disease progression; the secondary end point was 6 months. Secondary outcomes were selected on the basis of the theoretical underpinnings of CALM and prior research ${ }^{21,22}$ and included diagnosis of major depression, generalized anxiety, deathrelated anxiety, spiritual well-being, quality of life at the end of life, attachment security, couple communication, post-traumatic growth, and demoralization. 


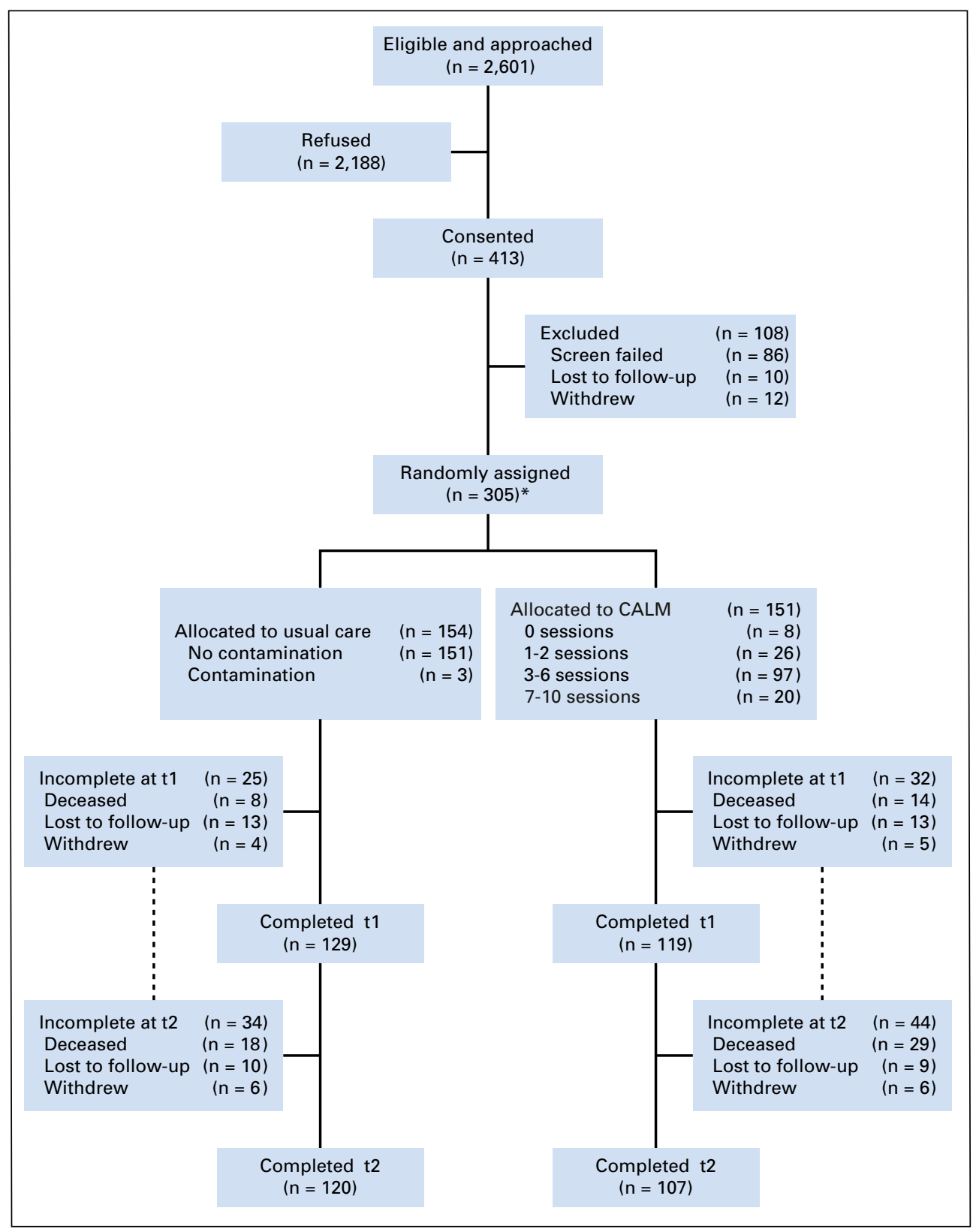

Fig 1. CONSORT diagram. $(*)$ Analyses by intention to treat. CALM, Managing Cancer And Living Meaningfully.

\section{METHODS}

\section{Study Design}

This unblinded, parallel assignment RCT had two trial conditions: intervention plus usual care (UC) versus UC alone, with assessments at baseline ( $\mathrm{t} 0$ ), 3 months ( $\mathrm{t} 1$; primary end point), and 6 months ( $\mathrm{t} 2$; trial end point). The trial protocol is provided in Lo et al. ${ }^{23}$ The site was the Princess Margaret Cancer Centre (PM), which is part of the University Health Network in Toronto, Ontario, Canada. This trial was approved by the University Health Network Research Ethics Board (REB \#09-0855-C) and registered with ClinicalTrials.gov.

\section{Participants}

Inclusion criteria were $\geq 18$ years of age; English fluency; no cognitive impairment; and diagnosis of stage III or IV lung cancer, any-stage pancreatic cancer (because of its aggressiveness), unresectable cholangiocarcinoma, unresectable liver cancer, unresectable ampullary or peri-ampullary cancer or other stage IV gastrointestinal (GI) cancer, stage III or IV ovarian and fallopian tube cancers or other stage IV gynecologic cancer, stage IV breast cancer, genitourinary cancer, sarcoma, melanoma, or endocrine cancer. Diagnoses were confirmed by chart review and consistent with an expected prognosis of 12 to 18 months on the basis of prior research in this population. ${ }^{22}$ Exclusion criteria were major communication difficulties, cognitive impairment on the basis of a Short Orientation-Memory-Concentration test score $<20,{ }^{24}$ current psychiatric or psychological treatment in the Department of Supportive Care at $\mathrm{PM}$, unwillingness to accept random assignment or to commit to the study, and prior participation in CALM therapy. Participants were approved for trial enrollment by the principal investigators before random assignment and provided written informed consent.

\section{Randomization and Masking}

Permuted block randomization was used to allocate participants, with stratification by Patient Health Questionnaire-9 (PHQ-9) score 


\begin{tabular}{|c|c|c|c|}
\hline Characteristic & UC, \% (No.) & CALM, \% (No.) & $P$ \\
\hline No. of participants $(n=305)$ & 154 & 151 & \\
\hline Mean age, years (SD) & $59.10(11.48)$ & 59.05 (10.55) & .97 \\
\hline Female & $60(92)$ & $60(90)$ & .98 \\
\hline White & 84 (129) & $84(127)$ & .94 \\
\hline Married/common law & 71 (109) & $72(108)$ & .96 \\
\hline Postsecondary education & 84 (129) & $82(123)$ & .68 \\
\hline $\begin{array}{l}\text { Mean duration of illness, } \\
\text { years }(S D)^{*}\end{array}$ & $1.68(2.12)$ & $1.49(1.74)$ & .39 \\
\hline Cancer type & & & .93 \\
\hline Breast & $8(13)$ & $9(13)$ & \\
\hline Lung & $12(18)$ & $16(24)$ & \\
\hline Sarcoma & $6(10)$ & $5(7)$ & \\
\hline Melanoma & 2 (3) & 2 (3) & \\
\hline Endocrine & $3(5)$ & $3(5)$ & \\
\hline GI & $26(40)$ & 26 (39) & \\
\hline Gynecologic & $27(41)$ & 22 (33) & \\
\hline Genitourinary & $16(24)$ & $18(27)$ & \\
\hline \multicolumn{4}{|l|}{ MSAS† } \\
\hline Mean symptom count (SD) & $12.88(4.33)$ & $12.57(5.08)$ & .57 \\
\hline Mean symptom severity $¥$ (SD) & $1.77(0.41)$ & $1.75(0.43)$ & .68 \\
\hline $\begin{array}{l}\text { Mean Karnofsky performance score§ } \\
\text { (SD) }\end{array}$ & $79.90(8.83)$ & $80.00(10.71)$ & .93 \\
\hline Antidepressant use & $18(28)$ & $10(15)$ & $.04 \|$ \\
\hline PHQ-9 $\geq 8$ points & $44(68)$ & $43(65)$ & .85 \\
\hline \multicolumn{4}{|c|}{ 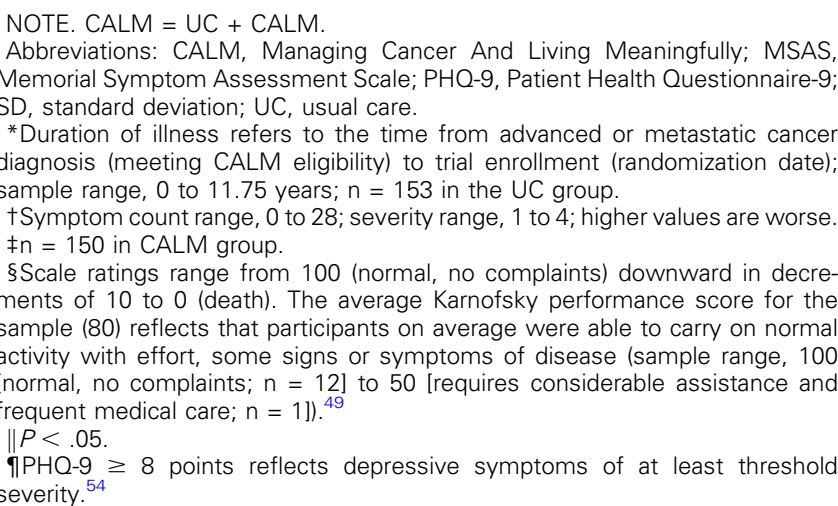 } \\
\hline
\end{tabular}

$(<10 \text { or } \geq 10)^{25}$ to ensure balance of moderate to severe depressive symptoms between arms. The PM Biostatistics Department, which is independent of the trial team, managed the randomization. Block sizes were variable and unknown to the research team. Computer-generated randomization assignments were provided by the Biostatistics Department after the participant's baseline assessment.

\section{Trial Conditions}

On the basis of earlier trials, ${ }^{18,19}$ most intervention participants were expected to receive three to six CALM psychotherapy sessions (each 45 to 60 minutes) over 3 to 6 months. The actual number of sessions each participant received was based on clinical judgment and the patient's ability to participate. Therapists aimed to deliver at least three sessions within the first 3 months of study enrollment. Noncompliance was defined as fewer than three sessions over the course of the trial. The primary caregiver was invited to one or more sessions when acceptable to the participant and therapist. Therapists were five master's degree-level social workers and three psychiatrists. CALM training involved a 2-day workshop and satisfactory completion of at least two cases under supervision with G.R. and S.H., codevelopers of the intervention. ${ }^{16}$ Treatment integrity was maintained through weekly group supervision, which included a review of session audiotapes and case discussion. After case presentations, G.R. and S.H. used a treatment integrity rating scale (Appendix, online only) adapted from Spiegel and Spira ${ }^{26}$ to assess the therapists, and these evaluations were discussed to improve competencies.

Participants in the control group received UC alone (see Table 1 for comparison with CALM), which included routine oncology treatment and follow-up and clinic-based distress screening. ${ }^{27-29}$ UC did not preclude referral for specialized psychosocial oncology services, but most patients with metastatic cancer at PM do not receive psychotherapy as part of UC. ${ }^{30}$

\section{Procedures}

Patients with advanced cancer were identified through prescreening of outpatient oncology clinic lists, and eligible patients were approached for recruitment during clinic appointments. After informed consent, research staff assessed cognitive functioning, readiness, and ability to participate, administered baseline measures, conducted a diagnostic interview for depression, and received enrollment approval from the study principal investigators before contacting the PM Biostatistics Department to receive randomization assignments. Participants were contacted at 3 and 6 months to complete follow-up assessments, which were conducted in person at the hospital, by telephone, or by mail. Assessments were scanned and scored by an independent data management company. The final data set was exported to the trial team and to a biostatistician at PM (not part of the trial team) for analysis and verification.

\section{Outcome Measures}

Primary outcome. The primary outcome was measured using the PHQ- $9,{ }^{25}$ a reliable and valid measure of Diagnostic and Statistical Manual of Mental Disorders, Fourth Edition (DSM-IV) ${ }^{31}$-concordant depression. The PHQ-9 has been widely used in patients with advanced cancer. ${ }^{32}$

Secondary outcomes. The secondary outcomes were measured with the following assessments:

Structured Clinical Interview for DSM-IV-TR Axis I Disorders (SCID), Research Version, ${ }^{33}$ a semistructured interview for the diagnosis of DSM-IV major depression ${ }^{31}$ (administered by research staff trained and supervised by M.L.)

Generalized Anxiety Disorder-7 (GAD-7), ${ }^{34}$ a widely used and validated measure to assess generalized anxiety symptoms

Death and Dying Distress Scale (DADDS), ${ }^{35}$ a valid measure in patients with advanced cancer ${ }^{36}$ that rates distress about the dying process, lost opportunities, and perceived burden on others

Functional Assessment of Chronic Illness Therapy-Spiritual Well-Being Scale (FACIT-Sp-12), ${ }^{37}$ a measure of spiritual well-being validated for use in cancer ${ }^{38}$ and widely used in palliative care research ${ }^{39}$

Quality of Life at the End of Life Cancer Scale (QUAL-EC), ${ }^{40}$ a short form of the Quality of Life at the End of Life assessment ${ }^{41}$; we used the following subscales relevant to psychosocial functioning: preparation for the end of life (ie, extent to which the family is prepared and financial plans made), relationship with health care providers (ie, extent to which patients feel informed and are able to participate in decisions about their care), and sense of life completion (ie, ability to share important things and to feel connected to others)

16-Item Experiences in Close Relationships Scale validated for use in advanced cancer (ECR-M16), ${ }^{42}$ a modified and brief version of the Experiences in Close Relationships assessment ${ }^{43}$ that measures attachment insecurity (ie, reflects difficulty in trusting and relying on close others in times of need $)^{44}$

Couple Communication Scale (CCS) ${ }^{45}$ for participants in long-term relationships, a part of the validated PREPARE/ENRICH Inventory ${ }^{45}$ that assesses the quality of communication in the dyad

Posttraumatic Growth Inventory (PTGI), ${ }^{46}$ a valid measure previously used in cancer to assess positive psychological changes after trauma ${ }^{47}$

Demoralization Scale (DS), ${ }^{48}$ a validated measure of the experience of disheartenment and helplessness

Additional data collected were demographics, medical history, Karnofsky performance status, ${ }^{49}$ and the presence and severity of 28 
Table 3. Primary Outcome and Its Clinical Effect

\begin{tabular}{|c|c|c|c|c|c|c|c|c|}
\hline Primary Outcome and Time Point & UC & CALM & $\Delta$ & $\begin{array}{c}\text { OR } \\
(\mathrm{CALM} v \cup \mathrm{C})\end{array}$ & $95 \% \mathrm{Cl}$ & $d$ & $P$ & Multiple Imputation $P$ \\
\hline \multicolumn{9}{|l|}{$\mathrm{PHQ}-9$} \\
\hline \multicolumn{9}{|l|}{ to } \\
\hline Mean (SD) & $7.41(4.75)$ & $7.45(4.96)$ & - & - & - & - & - & - \\
\hline No. of participants & 154 & 151 & & & & & & \\
\hline \multicolumn{9}{|l|}{$\mathrm{t} 1$} \\
\hline Mean (SD) & $7.01(4.82)$ & $5.97(4.83)$ & 1.09 & - & 0.04 to 2.13 & 0.23 & $.04^{*}$ & $.04^{*}$ \\
\hline No. of participants & 128 & 119 & & & & & & \\
\hline \multicolumn{9}{|l|}{ t2 } \\
\hline Mean (SD) & $6.64(4.97)$ & 5.35 (3.99) & 1.29 & - & 0.24 to 2.35 & 0.29 & $.02 *$ & $.007^{*}$ \\
\hline No. of participants & 118 & 107 & & & & & & \\
\hline \multicolumn{9}{|l|}{ Clinical impact, \% (frequency/No.) } \\
\hline \multicolumn{9}{|l|}{ PHQ-9 reduction $\geq$ MCID (5 points) $\dagger$} \\
\hline t1 & 33 (19 of 58$)$ & $52(27$ of 52$)$ & - & 2.22 & 1.02 to 4.80 & & $.04 *$ & \\
\hline t2 & 35 (19 of 54$)$ & $64(28$ of 44$)$ & - & 3.22 & 1.41 to 7.39 & & $.005^{*}$ & \\
\hline \multicolumn{9}{|l|}{ Remissiont } \\
\hline $\mathrm{t} 1$ & 38 (22 of 58$)$ & $56(29$ of 52$)$ & - & 2.06 & 0.96 to 4.42 & & .06 & \\
\hline t2 & 37 (20 of 54$)$ & 66 (29 of 44$)$ & - & 3.29 & 1.43 to 7.56 & & $.005^{*}$ & \\
\hline \multicolumn{9}{|l|}{ Emergenceł } \\
\hline $\mathrm{t} 1$ & $30(21$ of 70$)$ & 13 (9 of 67$)$ & - & 0.36 & 0.15 to 0.86 & & $.02 *$ & \\
\hline t2 & $19(12$ of 64$)$ & 11 (7 of 63$)$ & - & 0.54 & 0.20 to 1.48 & & .23 & \\
\hline \multicolumn{9}{|c|}{$\begin{array}{l}\text { NOTE. } \Delta \text { is the regression-estimated mean difference between groups controlled for baseline. Cohen's } d \text { (effect size) is the standardized mean difference. Effect sizes } \\
\text { of } 0.20 \text { to } 0.50 \text { are considered small to medium. }{ }^{51} \text { The analyses of clinical effect, including Cls for ORs, involved simple Pearson } \chi^{2} \text { tests without continuity correction. } \\
\text { CALM }=U C+\text { CALM. } \\
\text { Abbreviations: CALM, Managing Cancer And Living Meaningfully; MCID, minimal clinically important difference; OR, odds ratio; PHQ-9, Patient Health Questionnaire-9 } \\
\text { (score range, } 0 \text { to } 27 \text {; higher scores reflect greater depressive symptom severity); t0, baseline assessment; t1, 3-month assessment (primary end point); t2, } 6 \text {-month } \\
\text { assessment (trial end point); UC, usual care. } \\
{ }^{*} P<.05 \text {. } \\
\text { †In participants with depressive symptoms of at least threshold severity (PHQ-9 } \geq 8 \text { points) at baseline. } \\
\text { łIn participants with depressive symptoms less than threshold severity (PHQ-9 }<8 \text { points) at baseline. }\end{array}$} \\
\hline
\end{tabular}

common cancer symptoms assessed using a shortened version of the Memorial Symptom Assessment Scale. ${ }^{50}$

\section{Statistical Analysis}

A sample size recalculation was conducted in February 2014 using actual attrition and compliance rates rather than pretrial estimates and without examination of treatment effects. A total baseline sample of at least 242 participants would power this trial to detect a small to medium effect size (Cohen's $d)^{51}$ of $0.405 .{ }^{19}$ With available resources, we chose to extend recruitment to reach at least 100 trial completionists per arm, which was achieved after consenting 413 participants, 305 of whom were randomly assigned.

Analyses were by intention to treat. Analysis of covariance was used to examine outcome differences between trial arms at follow-up, controlling for baseline scores. The main analyses were conducted on available participants, $P$ values correspond to two-tailed tests and $\alpha$ was set at .05. As a sensitivity analysis, we used multiple imputation with the Markov model $^{52}$ to address the issue of missing data (Appendix Table A1, online only) and report $P$ values that tested the aggregate results of $20 \mathrm{impu}-$ tations, which achieved 0.99 relative efficiency on the primary outcome and stabilized estimates. The imputation model included the relevant $t 0$, $\mathrm{t} 1$, and $\mathrm{t} 2$ outcome assessments and randomization. We used the false discovery rate $(\mathrm{FDR})^{53}$ method to control for multiple comparisons on the secondary outcomes and report FDR-adjusted $P$ values. The FDR was applied separately to the family of tests at 3 and 6 months. The familywise FDR was set to .05. Trial analyses were independently verified by a member of the PM Biostatistics Department. Analyses for this article were generated using SAS/STAT 9.3 statistical software (SAS Institute, Cary, NC).

To clarify the clinical meaning of effects on the primary outcome, we conducted post hoc analyses with regard to the emergence and remission rates of depressive symptoms of at least threshold severity (indicated by $\mathrm{PHQ}-9 \geq 8$ points), ${ }^{54}$ and the proportion of patients with a PHQ-9 reduction greater than the minimal clinically important difference (MCID) of 5 points ${ }^{55}$ in participants with depressive symptoms of at least threshold severity. Prespecified subanalyses were conducted for groups with low, moderate, or high death anxiety at baseline (using DADDS cutoffs of $<25$ and $\geq 47$ points to distinguish approximately the upper and lower thirds of the sample) because these groups may differ in the processing of death-related distress. ${ }^{56}$ Finally, mixed models were conducted as supplementary analyses to examine treatment effects across outcomes, regressing each outcome on trial arm (UC, CALM), time ( $\mathrm{t} 0, \mathrm{t} 1, \mathrm{t} 2)$, and their interaction, with intercepts set as random effects.

\section{RESULTS}

Four hundred and thirteen patients consented to participate between February 3, 2012, and March 4, 2016, 305 of whom were randomly assigned to CALM $(n=151)$ and UC $(n=154$; Fig 1$)$. Contamination (defined as two or more psychotherapy sessions with a CALM-trained PM clinician) was $2 \%$ in control participants. Participation in at least three sessions was considered a minimal intervention. On the basis of this criterion, compliance with the intervention was $54.3 \%$ in the CALM group at 3 months (mean, 3 sessions; range, 0 to 7 sessions) and $77.5 \%$ by 6 months (mean, 4 sessions; range, 0 to 10 sessions). Of those who received three or more sessions over 6 months, $64.2 \%$ received three to six sessions and $13.3 \%$ received seven to 10 sessions; of the remaining CALM participants, $17.2 \%$ received one or two sessions and 5.3\% received no sessions. The majority of sessions were delivered in outpatient clinics; a small number were delivered to very ill 


\begin{tabular}{|c|c|c|c|c|c|c|}
\hline Secondary Outcome & UC & CALM & $\Delta$ & $95 \% \mathrm{Cl}$ & $d$ & $P$ \\
\hline \multicolumn{7}{|l|}{ SCID: major depression* } \\
\hline \multicolumn{7}{|l|}{ to } \\
\hline$\%$ (No.) & $8(12)$ & $4(6)$ & - & - & - & - \\
\hline No. of participants & 154 & 149 & & & & \\
\hline \multicolumn{7}{|l|}{$\mathrm{t} 1$} \\
\hline$\%($ No.) & $6(8)$ & $2(2)$ & - & - & - & - \\
\hline No. of participants & 125 & 117 & & & & \\
\hline \multicolumn{7}{|l|}{ t2 } \\
\hline$\%(\mathrm{No})$. & 3 (3) & $1(1)$ & - & - & - & - \\
\hline No. of participants & 114 & 106 & & & & \\
\hline \multicolumn{7}{|l|}{ GAD-7: generalized anxiety } \\
\hline \multicolumn{7}{|l|}{ t0 } \\
\hline Mean (SD) & $5.84(4.31)$ & $5.31(3.63)$ & - & - & - & - \\
\hline No. of participants & 153 & 151 & & & & \\
\hline \multicolumn{7}{|l|}{ t1 } \\
\hline Mean (SD) & $5.56(4.66)$ & $4.47(3.75)$ & 0.64 & -0.32 to 1.59 & 0.15 & .19 \\
\hline No. of participants & 121 & 113 & & & & \\
\hline \multicolumn{7}{|l|}{ t2 } \\
\hline Mean (SD) & $5.48(4.68)$ & $4.37(4.10)$ & 0.79 & -0.26 to 1.85 & 0.18 & .14 \\
\hline No. of participants & 113 & 103 & & & & \\
\hline \multicolumn{7}{|l|}{ DADDS: death anxiety (total sample) } \\
\hline \multicolumn{7}{|l|}{ to } \\
\hline Mean (SD) & $35.64(16.88)$ & 33.77 (16.89) & - & - & - & - \\
\hline No. of participants & 154 & 151 & & & & \\
\hline \multicolumn{7}{|l|}{ t1 } \\
\hline Mean (SD) & $30.66(18.00)$ & 27.39 (16.85) & 1.60 & -1.91 to 5.11 & 0.09 & .37 \\
\hline No. of participants & 123 & 114 & & & & \\
\hline \multicolumn{7}{|l|}{ t2 } \\
\hline Mean (SD) & $30.40(17.61)$ & $27.80(18.16)$ & 1.83 & -1.99 to 5.64 & 0.10 & .35 \\
\hline No. of participants & 115 & 102 & & & & \\
\hline FACIT-Sp-12: spiritual well-being & & & & & & \\
\hline to & & & & & & \\
\hline Mean (SD) & $29.60(8.76)$ & $28.69(8.65)$ & - & - & - & - \\
\hline No. of participants & 154 & 151 & & & & \\
\hline $\mathrm{t} 1$ & & & & & & \\
\hline Mean (SD) & $31.19(9.17)$ & $30.77(8.27)$ & -0.52 & -2.05 to 1.01 & 0.06 & .50 \\
\hline No. of participants & 121 & 113 & & & & \\
\hline t2 & & & & & & \\
\hline Mean (SD) & $30.50(9.62)$ & $31.09(8.29)$ & -1.43 & -3.17 to 0.30 & 0.16 & .11 \\
\hline No. of participants & 116 & 103 & & & & \\
\hline QUAL-EC: preparation for end of life & & & & & & \\
\hline to & & & & & & \\
\hline Mean (SD) & $11.62(3.78)$ & $12.07(3.73)$ & - & - & - & - \\
\hline No. of participants & 154 & 151 & & & & \\
\hline $\mathrm{t} 1$ & & & & & & \\
\hline Mean (SD) & $11.72(3.84)$ & $13.01(3.75)$ & -0.99 & -1.68 to -0.29 & 0.26 & $.007 \dagger$ \\
\hline No. of participants & 121 & 113 & & & & \\
\hline t2 & & & & & & \\
\hline Mean (SD) & $12.17(3.97)$ & $13.49(3.50)$ & -1.20 & -1.92 to -0.48 & 0.32 & $.001 \dagger$ \\
\hline No. of participants & 115 & 103 & & & & \\
\hline QUAL-EC: relationship with health & & & & & & \\
\hline to & & & & & & \\
\hline Mean (SD) & $17.23(3.70)$ & $17.28(3.94)$ & - & - & - & - \\
\hline No. of participants & 154 & 151 & & & & \\
\hline $\mathrm{t} 1$ & & & & & & \\
\hline Mean (SD) & $18.15(3.86)$ & $17.17(4.04)$ & 0.82 & 0.04 to 1.61 & 0.21 & $.04 \dagger$ \\
\hline No. of participants & 121 & 113 & & & & \\
\hline t2 & & & & & & \\
\hline Mean (SD) & $18.05(3.76)$ & $17.71(3.84)$ & 0.12 & -0.68 to 0.91 & 0.03 & .73 \\
\hline No. of participants & 115 & 102 & & & & \\
\hline $\begin{array}{l}\text { QUAL-EC: life completion } \\
\text { t0 }\end{array}$ & & & & & & \\
\hline Mean (SD) & 18.23 (3.79) & $18.53(4.00)$ & - & - & - & - \\
\hline No. of participants & 154 & 151 & & & & \\
\hline t1 & & & & & & \\
\hline Mean (SD) & $18.62(3.72)$ & $18.08(4.04)$ & 0.55 & -0.26 to 1.37 & 0.14 & .18 \\
\hline No. of participants & 121 & 113 & & & & \\
\hline & (conti & n following pag & & & & \\
\hline
\end{tabular}




\begin{tabular}{|c|c|c|c|c|c|c|}
\hline Secondary Outcome & UC & CALM & $\Delta$ & $95 \% \mathrm{Cl}$ & $d$ & $P$ \\
\hline \multicolumn{7}{|l|}{ t2 } \\
\hline Mean (SD) & $18.72(3.83)$ & $18.47(3.88)$ & 0.17 & -0.62 to 0.96 & 0.04 & .67 \\
\hline No. of participants & 115 & 103 & & & & \\
\hline \multicolumn{7}{|l|}{$\begin{array}{l}\text { ECR-M16: attachment insecurity } \\
\text { t0 }\end{array}$} \\
\hline Mean (SD) & 44.50 (15.03) & $42.60(14.64)$ & - & - & - & - \\
\hline No. of participants & 154 & 151 & & & & \\
\hline \multicolumn{7}{|l|}{$\mathrm{t} 1$} \\
\hline Mean (SD) & 43.64 (15.73) & $41.13(13.91)$ & 1.24 & -1.63 to 4.12 & 0.08 & .39 \\
\hline No. of participants & 121 & 113 & & & & \\
\hline \multicolumn{7}{|l|}{ t2 } \\
\hline Mean (SD) & $44.14(16.19)$ & $40.66(12.71)$ & 2.83 & -0.15 to 5.80 & 0.19 & .06 \\
\hline No. of participants & 116 & 101 & & & & \\
\hline \multicolumn{7}{|l|}{ CCS: couple communication } \\
\hline \multicolumn{7}{|l|}{ to } \\
\hline Mean (SD) & $36.48(8.20)$ & $39.15(6.99)$ & - & - & - & - \\
\hline No. of participants & 115 & 120 & & & & \\
\hline \\
\hline Mean (SD) & $38.38(7.63)$ & $38.32(7.61)$ & 1.73 & 0.10 to 3.37 & 0.23 & $.04 t$ \\
\hline No. of participants & 91 & 92 & & & & \\
\hline \multicolumn{7}{|l|}{ t2 } \\
\hline Mean (SD) & $38.31(7.79)$ & $38.44(7.69)$ & 1.37 & -0.30 to 3.04 & 0.18 & .11 \\
\hline No. of participants & 81 & 84 & & & & \\
\hline \multicolumn{7}{|l|}{ PTGI: post-traumatic growth } \\
\hline \multicolumn{7}{|l|}{ to } \\
\hline Mean (SD) & $54.93(21.28)$ & $49.16(21.32)$ & - & - & - & - \\
\hline No. of participants & 154 & 151 & & & & \\
\hline \\
\hline Mean (SD) & $56.72(22.29)$ & 50.56 (23.76) & 0.27 & -3.88 to 4.43 & 0.01 & .90 \\
\hline No. of participants & 120 & 112 & & & & \\
\hline \multicolumn{7}{|l|}{ t2 } \\
\hline Mean (SD) & 54.18 (23.64) & $51.68(21.72)$ & -1.35 & -6.13 to 3.43 & 0.06 & .58 \\
\hline No. of participants & 115 & 103 & & & & \\
\hline \multicolumn{7}{|l|}{ DS: demoralization } \\
\hline \multicolumn{7}{|l|}{ t0 } \\
\hline Mean (SD) & $28.41(14.24)$ & $27.03(13.52)$ & - & - & - & - \\
\hline No. of participants & 154 & 151 & & & & \\
\hline \multicolumn{7}{|l|}{$\mathrm{t} 1$} \\
\hline Mean (SD) & $25.46(14.10)$ & $24.97(14.54)$ & -0.37 & -3.12 to 2.38 & 0.03 & .80 \\
\hline No. of participants & 119 & 113 & & & & \\
\hline \multicolumn{7}{|l|}{ t2 } \\
\hline Mean (SD) & $25.76(14.47)$ & $23.15(15.04)$ & 2.34 & -0.51 to 5.19 & 0.16 & .11 \\
\hline No. of participants & 116 & 103 & & & & \\
\hline \multicolumn{7}{|c|}{ 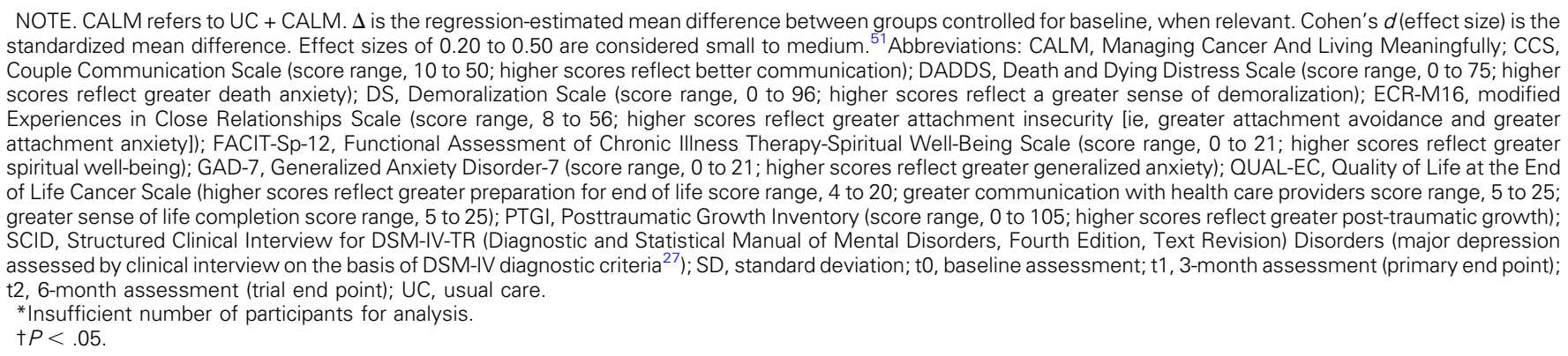 } \\
\hline
\end{tabular}

participants by telephone or in the inpatient palliative care unit. Mean treatment integrity ratings indicated that most therapeutic competencies were satisfactory to excellent, with the most room for improvement in the offering of interpretations (Appendix Fig A1, online only). The overall attrition rate at 6 months (trial end point) was $25.5 \%$ (15.4\% died, $6.2 \%$ were lost to follow-up, and 3.9\% withdrew), with $70.9 \%$ of the CALM group and $77.9 \%$ of the UC group completing the trial. Final trial follow-ups were completed by September 2016. Mortality 1 year after trial completion was $67.5 \%$ (206 of 305 participants [109 CALM participants, 97 UC participants]).

No trial group differences existed at baseline (Table 2), except for antidepressant use (18\% UC $v 10 \%$ CALM). Preliminary analyses that controlled for this factor found that it was nonsignificant and did not affect the pattern and magnitude of findings; therefore, we report group differences without 
covariables. Of note, as the study progressed, the group difference on antidepressant use was nonsignificant at 3 months (UC, 19.5\% [25 of 128]; CALM, 11.8\% [14 of 119]; $P=.09$ ) and at 6 months (UC, $17.1 \%$ [20 of 117]; CALM, 12.3\% [13 of 106]; $P=.31$ ).

Table 3 lists primary outcome results. The CALM group reported less-severe depressive symptoms than the UC group at the primary end point of 3 months $(d=0.23 ; P=.04)$. This effect appeared to be greater at 6 months $(d=0.29 ; P=.02)$. Analysis of multiple imputations yielded the same patterns of effect.

To clarify clinical meaning, we conducted post hoc analyses of remission and emergence rates of at least threshold depression (PHQ-9 $\geq 8$ points $^{54}$; Table 3 ). CALM participants were more likely to show remission of symptoms of at least threshold severity at 6 months (odds ratio $[\mathrm{OR}], 3.29 ; P=.005$ ) and were less likely to develop depressive symptoms of at least threshold severity at 3 months $(\mathrm{OR}, 0.36 ; P=.02)$. For participants with depressive symptoms of at least threshold severity, CALM was more likely to provide a clinically important PHQ-9 reduction (minimal clinically important difference [MCID], 5 points) ${ }^{55}$ at 3 months (OR, 2.22; $P=.04)$ and at 6 months (OR, 3.22; $P=.005)$.

Table 4 lists the secondary outcomes, and Table 5 lists the FDR-adjusted $P$ values and multiple imputation results. With a focus on the most robust findings, a significant treatment effect was found for preparation for end of life at both 3 and 6 months in CALM participants compared with UC that was sustained after multiple imputation, although the 3-month effect was rendered nonsignificant after controlling for multiple comparisons. No adverse effects were reported. Some outcomes (couple communication and relationship with health care providers) were better in the UC group at 3 months, although these effects were rendered nonsignificant after multiple imputations and controlling for multiple comparisons and were not sustained at 6 months.

The sample was stratified into low, moderate, and high groups for death anxiety subanalyses. Within each stratum, we tested for treatment effects on secondary outcomes associated with death anxiety. ${ }^{35,36,56}$ CALM participants with moderate death anxiety had significantly lower DADDS scores at both 3 and 6 months than UC participants ( $d=0.46$ and 0.68 , respectively). At 6 months, CALM participants also reported less generalized anxiety and demoralization and greater spiritual well-being and attachment security than UC participants in the same DADDS range ( $d$ range, 0.43 to 0.50 ; Table 6 ). No other effects were found in the lowest and highest death anxiety strata (Appendix Table A2, online only).

Results from the mixed-model supplementary analyses supported the main analyses. Appendix Table A3 (online only) lists trial arm $\times$ time interactions for all outcomes. The CALM group was expected to show less distress and greater benefit over time relative to the UC group. Significant effects on depressive symptoms, preparation for end of life, and CCS were found. Appendix Table A4 (online only) lists the mixed-model estimated means that explain the significant trial arm $\times$ time interactions. The CALM group showed a pattern of steeper decline in depressive symptoms and greater end-of-life preparation over time than the UC group. With regard to the CCS, the two groups seemed to differ at baseline and came to parity over time.

\begin{tabular}{|c|c|c|c|}
\hline Secondary Outcome by Time & $P$ & $\begin{array}{c}\text { FDR- } \\
\text { Adjusted } P\end{array}$ & $\begin{array}{c}\text { Multiple } \\
\text { Imputation } P\end{array}$ \\
\hline \multicolumn{4}{|l|}{ t1 } \\
\hline QUAL-EC: preparation for end of life & $.007^{*}$ & .07 & $.009 *$ \\
\hline CCS & $.04^{*}$ & .13 & .06 \\
\hline $\begin{array}{l}\text { QUAL-EC: relationship with health } \\
\text { care provider }\end{array}$ & $.04^{*}$ & .13 & .07 \\
\hline QUAL-EC: life completion & .18 & .38 & .26 \\
\hline GAD-7 & .19 & .38 & .11 \\
\hline DADDS & .37 & .56 & .45 \\
\hline ECR-M16 & .39 & .56 & .38 \\
\hline FACIT-Sp-12 & .50 & .63 & .44 \\
\hline DS: demoralization & .79 & .88 & .90 \\
\hline PTGI & .90 & .90 & .93 \\
\hline \multicolumn{4}{|l|}{ t2 } \\
\hline $\begin{array}{l}\text { QUAL-EC: preparation for } \\
\text { end-of-life }\end{array}$ & $.001^{*}$ & $.01^{*}$ & $<.001^{*}$ \\
\hline ECR-M16 & .06 & .22 & .06 \\
\hline $\operatorname{CCS}$ & .11 & .22 & .13 \\
\hline FACIT-Sp-12 & .11 & .22 & .15 \\
\hline DS: demoralization & .11 & .22 & .09 \\
\hline GAD-7 & .14 & .23 & .12 \\
\hline DADDS & .35 & .50 & .48 \\
\hline PTGI & .58 & .73 & .71 \\
\hline QUAL-EC: life completion & .67 & .73 & .57 \\
\hline $\begin{array}{l}\text { QUAL-EC: relationship with } \\
\text { health care provider }\end{array}$ & .73 & .73 & .50 \\
\hline
\end{tabular}

Abbreviations: CCS, Couple Communication Scale; DADDS, Death and Dying Distress Scale; DS, Demoralization Scale; ECR-M16, modified Experiences in Close Relationships Scale; FACIT-Sp-12, Functional Assessment of Chronic Illness Therapy-Spiritual Well-Being Scale; FDR, false discovery rate; GAD-7, Generalized Anxiety Disorder-7; PTGI, Posttraumatic Growth Inventory; QUALEC, Quality of Life at the End of Life Cancer Scale; t1, 3-month assessment (primary end point); t2, 6-month assessment (trial end point).

\section{DISCUSSION}

In this RCT of a tailored supportive-expressive therapy for patients with advanced disease and expected prognosis of at least 12 months, ${ }^{22}$ we found significant improvement in the intervention group in the severity of depressive symptoms at 3 months compared with UC, with an apparently greater effect at 6 months compared with UC. CALM was effective in achieving clinically important reductions in depressive symptom severity at 3 and 6 months in participants with at least threshold symptoms and in the rate of remission of threshold symptoms by trial end. We also found a significant treatment effect that favored CALM at the 6-month end point for greater end-of-life preparation compared with UC.

Among participants who were not depressed at baseline, those who received CALM were less likely to report threshold symptoms at the primary end point, which suggests that CALM may help to prevent the onset of depressive symptoms that may otherwise grow over time in individuals with advanced disease. ${ }^{55}$ Although some have suggested the restriction of depression intervention trials in cancer to participants with major depression to avoid floor effects, ${ }^{57}$ this approach may obscure effects on prevention of depressive symptoms in patients without depression.

Evidence with regard to the mechanisms by which CALM exerts its effects will be reported in a separate publication. These mechanisms may include the opportunity for participants to discuss communication with health care providers, to address the 


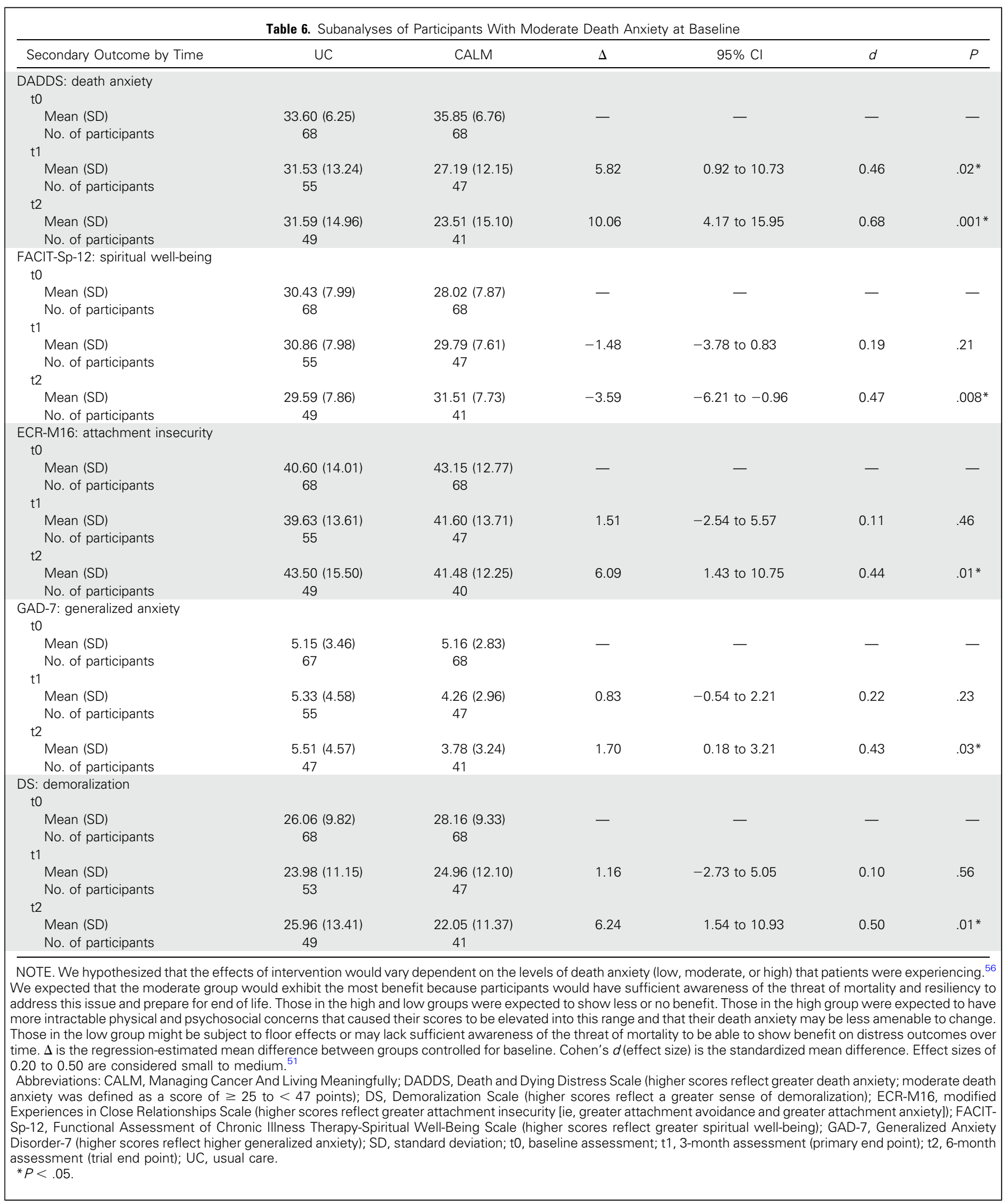

effect of their disease on their self-concept and family relationships, to find or reclaim a sense of meaning and purpose in life, to express and manage fears and wishes related to the end of life, and to begin preparations for end of life. CALM addresses these concerns to alter what we have termed a final common pathway of distress that leads to depression in this population. ${ }^{21}$ Such a targeted approach is 
consistent with the view that positive outcomes and sustained improvement are most likely to occur when the treatment of depression is directed at etiologic and pathogenic factors ${ }^{58}$ and at subsystems of variables that interact in specific contexts. ${ }^{59}$

The study findings suggest that participants with moderate levels of distress about dying and death benefited most from CALM therapy in terms of reduction of such distress and improvement on the secondary outcomes of generalized anxiety, demoralization, spiritual well-being, and attachment security. Those with the lowest levels of death-related distress may be managing deathrelated concerns effectively and/or may be nonreflective about them; those with the highest levels may feel too overwhelmed to be able or willing to participate in conversations about such issues. ${ }^{56}$ Additional research is needed to clarify which patients might benefit most from CALM and to identify the optimal point in the disease trajectory for CALM to be initiated.

Limitations of this study include that it was conducted at a single site in a large Canadian city with primarily English-speaking, white, well-educated participants, who may not be representative of other settings. The recruitment rate from oncology clinics is comparable to that with other psychotherapeutic interventions in similar settings, ${ }^{60}$ although this may limit the generalizability of the findings. Strengths include the relatively high intervention compliance and completion rates. More than $77 \%$ of participants randomly assigned to CALM were compliant with the intervention, and only $10 \%$ of those withdrew or were lost to follow-up over 6 months, mainly as a result of disease progression.
In summary, the findings of this RCT suggest that CALM therapy may help to relieve and prevent depressive symptoms in individuals with advanced disease and help patients to address preparations for the end of life. Additional research is needed to explore the optimal timing of CALM, the specific mechanisms of therapeutic action, the most appropriate and meaningful outcome measures, and feasibility and effectiveness of CALM in diverse cultural and clinical settings.

\section{AUTHORS' DISCLOSURES OF POTENTIAL CONFLICTS OF INTEREST}

Disclosures provided by the authors are available with this article at jco.org.

\section{AUTHOR CONTRIBUTIONS}

Conception and design: Gary Rodin, Christopher Lo, Anne Rydall, Carmine Malfitano, Aubrey Chiu, Tania Panday, Rinat Nissim, Madeline Li, Camilla Zimmermann, Sarah Hales

Collection and assembly of data: Anne Rydall, Joanna Shnall, Carmine Malfitano, Aubrey Chiu, Tania Panday, Sarah Watt, Ekaterina An

Data analysis and interpretation: Gary Rodin, Christopher Lo, Madeline Li, Sarah Hales

Manuscript writing: All authors

Final approval of manuscript: All authors

Accountable for all aspects of the work: All authors

\section{REFERENCES}

1. Rodin G: Individual psychotherapy for the patient with advanced disease, in Chochinov $\mathrm{H}$, Breitbart W (eds): Handbook of Psychiatry in Palliative Medicine. London, UK, Oxford University Press, 2009, pp 443-453

2. Temel JS, Greer JA, Muzikansky A, et al: Early palliative care for patients with metastatic non-smallcell lung cancer. N Engl J Med 363:733-742, 2010

3. Temel JS, Greer JA, El-Jawahri A, et al: Effects of early integrated palliative care in patients with lung and GI cancer: A randomized clinical trial. J Clin Oncol 35:834-841, 2017

4. Zimmermann C, Swami N, Krzyzanowska M, et al: Early palliative care for patients with advanced cancer: A cluster-randomised controlled trial. Lancet 383:1721-1730, 2014

5. Spiegel D, Bloom JR, Yalom I: Group support for patients with metastatic cancer. A randomized outcome study. Arch Gen Psychiatry 38:527-533, 1981

6. Spiegel D, Classen C. Group Therapy for Cancer Patients: A Research-Based Handbook of Psychosocial Care. New York, NY, Basic Books, 2000

7. Classen C, Butler LD, Koopman C, et al: Supportive-expressive group therapy and distress in patients with metastatic breast cancer: A randomized clinical intervention trial. Arch Gen Psychiatry 58: 494-501, 2001

8. Akechi $T$, Okuyama $T$, Onishi J, et al: Psychotherapy for depression among incurable cancer patients. Cochrane Database Syst Rev (2): CD005537, 2008

9. Li M, Kennedy EB, Byrne N, et al: Systematic review and meta-analysis of collaborative care interventions for depression in patients with cancer. Psychooncology 26:573-587, 2017

10. Okuyama T, Akechi T, Mackenzie L, et al: Psychotherapy for depression among advanced, incurable cancer patients: A systematic review and meta-analysis. Cancer Treat Rev 56:16-27, 2017

11. Chochinov HM, Hack $T$, Hassard $T$, et al: Dignity therapy: A novel psychotherapeutic intervention for patients near the end of life. J Clin Oncol 23:5520-5525, 2005

12. Breitbart W, Gibson C, Poppito SR, et al: Psychotherapeutic interventions at the end of life: $A$ focus on meaning and spirituality. Can J Psychiatry 49:366-372, 2004

13. Breitbart W, Rosenfeld $B$, Pessin $H$, et al: Meaning-centered group psychotherapy: An effective intervention for improving psychological wellbeing in patients with advanced cancer. J Clin Oncol 33:749-754, 2015

14. Breitbart W, Poppito $S$, Rosenfeld B, et al: Pilot randomized controlled trial of individual meaningcentered psychotherapy for patients with advanced cancer. J Clin Oncol 30:1304-1309, 2012

15. Chochinov HM, Kristjanson LJ, Breitbart W, et al: Effect of dignity therapy on distress and end-oflife experience in terminally ill patients: A randomised controlled trial. Lancet Oncol 12:753-762, 2011

16. Hales S, Lo C, Rodin G. Managing Cancer And Living Meaningfully (CALM) Treatment Manual: An Individual Psychotherapy for Patients with Advanced Cancer. Toronto, Ontario, Canada, Princess Margaret Cancer Centre, University Health Network, 2015

17. Hales S, Lo C, Rodin G: Managing Cancer And Living Meaningfully (CALM) therapy, in Holland JC, Breitbart WS, Butow PN, et al (eds), Psycho-Oncology. New York, NY, Oxford University Press,. 2015, pp 487-491
18. Lo C, Hales S, Jung J, et al: Managing Cancer And Living Meaningfully (CALM): Phase 2 trial of a brief individual psychotherapy for patients with advanced cancer. Palliat Med 28:234-242, 2014

19. Lo C, Hales S, Chiu A, et al: Managing Cancer And Living Meaningfully (CALM): Randomised feasibility trial in patients with advanced cancer. BMJ Support Palliat Care 10.1136/bmjspcare-2015000866 [epub ahead of print on January 19, 2016]

20. Nissim R, Freeman E, Lo $C$, et al: Managing Cancer And Living Meaningfully (CALM): A qualitative study of a brief individual psychotherapy for individuals with advanced cancer. Palliat Med 26: 713-721, 2012

21. Rodin G, Lo C, Mikulincer M, et al: Pathways to distress: The multiple determinants of depression, hopelessness, and the desire for hastened death in metastatic cancer patients. Soc Sci Med 68:562-569, 2009

22. Lo C, Zimmermann C, Rydall A, et al: Longitudinal study of depressive symptoms in patients with metastatic gastrointestinal and lung cancer. $\mathrm{J}$ Clin Oncol 28:3084-3089, 2010

23. Lo $C$, Hales $S$, Rydall $A$, et al: Managing Cancer And Living Meaningfully: Study protocol for a randomized controlled trial. Trials 16:391, 2015

24. Katzman R, Brown $T$, Fuld $P$, et al: Validation of a short Orientation-Memory-Concentration Test of cognitive impairment. Am J Psychiatry 140:734-739, 1983

25. Kroenke K, Spitzer RL, Williams JBW: The PHO-9: Validity of a brief depression severity measure. J Gen Intern Med 16:606-613, 2001

26. Spiegel D, Spira P. Supportive-Expressive Group Therapy: A Treatment Manual of Psychosocial Intervention for Women With Recurrent Breast 
Cancer. Stanford, CA, Psychosocial Treatment Laboratory, Department of Psychiatry and Behavioral Sciences, Stanford University School of Medicine, 1991

27. Li M, Macedo A, Crawford S, et al: Easier said than done: Keys to successful implementation of the Distress Assessment and Response Tool (DART) program. J Oncol Pract 12:e513-e526, 2016

28. Zimmermann C, Seccareccia D, Clarke A, et al: Bringing palliative care to a Canadian cancer center: The palliative care program at Princess Margaret Hospital. Support Care Cancer 14:982-987, 2006

29. Hannon B, Swami N, Pope A, et al: The oncology palliative care clinic at the Princess Margaret Cancer Centre: An early intervention model for patients with advanced cancer. Support Care Cancer 23:1073-1080, 2015

30. Ellis J, Lin J, Walsh A, et al: Predictors of referral for specialized psychosocial oncology care in patients with metastatic cancer: The contributions of age, distress, and marital status. J Clin Oncol 27: 699-705, 2009

31. American Psychiatric Association: Diagnostic and Statistical Manual of Mental Disorders, Fourth Edition, Text Revision (DSM-IV-TR). Washington, DC, American Psychiatric Publishing, 2000

32. Ell K, Xie B, Quon B, et al: Randomized controlled trial of collaborative care management of depression among low-income patients with cancer. J Clin Oncol 26:4488-4496, 2008

33. First MB, Spitzer RL, Gibbon $M$, et al: Structured Clinical Interview for DSM-IV-TR Axis I Disorders, Research Version, Non-Patient Edition. (SCID-I/ NP). New York, NY, Biometrics Research, New York State Psychiatric Institute, 2010

34. Spitzer RL, Kroenke K, Williams JBW, et al: A brief measure for assessing generalized anxiety disorder: The GAD-7. Arch Intern Med 166: 1092-1097, 2006

35. Lo C, Hales S, Zimmermann C, et al: Measuring death-related anxiety in advanced cancer: Preliminary psychometrics of the Death and Dying Distress Scale. J Pediatr Hematol Oncol 33: S140-S145, 2011 (suppl 2)

36. Krause $S$, Rydall $A$, Hales $S$, et al: Initial validation of the Death and Dying Distress Scale for the assessment of death anxiety in patients with advanced cancer. J Pain Symptom Manage 49 126-134, 2015

37. Peterman $A H$, Fitchett $G$, Brady $M J$, et al: Measuring spiritual well-being in people with cancer: The functional assessment of chronic illness therapySpiritual Well-Being Scale (FACIT-Sp). Ann Behav Med 24:49-58, 2002

38. Canada $A L$, Murphy PE, Fitchett $G$, et al: $A$ 3-factor model for the FACIT-Sp. Psychooncology 17 908-916, 2008

39. Breitbart W, Rosenfeld B, Gibson C, et al: Meaning-centered group psychotherapy for patients with advanced cancer: A pilot randomized controlled trial. Psychooncology 19:21-28, 2010

40. Lo C, Burman D, Swami N, et al: Validation of the QUAL-EC for assessing quality of life in patients with advanced cancer. Eur J Cancer 47:554-560, 2011

41. Steinhauser $K E$, Bosworth $H B$, Clipp EC, et al: Initial assessment of a new instrument to measure quality of life at the end of life. J Palliat Med 5 : 829-841, 2002

42. Lo $C$, Walsh $A$, Mikulincer $M$, et al: Measuring attachment security in patients with advanced cancer: Psychometric properties of a modified and brief Experiences in Close Relationships scale. Psychooncology 18:490-499, 2009

43. Brennan KA, Clark CL, Shaver PR: Self-report measurement of adult attachment: An integrative overview, in Simpson JA, Rholes WS (eds), Attachment Theory and Close Relationships. New York, NY, Guilford, 1998:pp. 46-76.

44. Philipp R, Vehling S, Scheffold $K$, et al: Attachment insecurity in advanced cancer patients: Psychometric properties of the German version of the Brief Experiences in Close Relationships Scale (ECRM16-G). J Pain Symptom Manage 54:555-562, 2017

45. Olson DH, Larson PJ: PREPARE/ENRICH: Customized Version. Minneapolis, MN, Life Innovations, 2009

46. Tedeschi RG, Calhoun LG: The Posttraumatic Growth Inventory: Measuring the positive legacy of trauma. J Trauma Stress 9:455-471, 1996

47. Stanton $A L$, Bower JE, Low CA: Posttraumatic growth after cancer, in Calhoun LG, Tedeschi RG (eds), Handbook of Posttraumatic Growth. New York, NY, Psychology Press, 2014, pp 138-175
8. Kissane DW, Wein S, Love A, et al: The Demoralization Scale: A report of its development and preliminary validation. J Palliat Care 20:269-276, 2004

49. Karnofsky D, Burchenal JH: The clinical evaluation of chemotherapeutic agents in cancer, in MacLeod CM (ed), Evaluation of Chemotherapeutic Agents. New York, NY, Columbia University Press, 1949, pp 191-205

50. Portenoy RK, Thaler HT, Kornblith $A B$, et al: The Memorial Symptom Assessment Scale: An instrument for the evaluation of symptom prevalence, characteristics and distress. Eur J Cancer 30A:1326-1336, 1994

51. Cohen J. Statistical Power Analyses for the Behavioral Sciences (ed 2). Hillsdale, NJ, Lawrence Erlbaum, 1988

52. SAS/STAT(R) 9.3 User's Guide: SAS Online Doc about PROC MI. http://support.sas.com/documentation/ cdl/en/statug/63962/HTML/default/viewer.htm\#statug_ mi_sect001.htm

53. Benjamini $Y$, Hochberg $Y$ : Controlling the false discovery rate: A practical and powerful approach to multiple testing. J R Stat Soc B 57:289-300, 1995

54. Thekkumpurath $P$, Walker J, Butcher I, et al: Screening for major depression in cancer outpatients: The diagnostic accuracy of the 9-item patient health questionnaire. Cancer 117:218-227, 2011

55. Löwe B, Unützer J, Callahan $\mathrm{CM}$, et al: Monitoring depression treatment outcomes with the Patient Health Questionnaire-9. Med Care 42: 1194-1201, 2004

56. Tong E, Deckert A, Gani N, et al: The meaning of self-reported death anxiety in advanced cancer. Palliat Med 30:772-779, 2016

57. Andrykowski MA, Manne SL: Are psychological interventions effective and accepted by cancer patients? I. Standards and levels of evidence. Ann Behav Med 32:93-97, 2006

58. Luyten P, Blatt SJ, Van Houdenhove B, et al: Depression research and treatment: Are we skating to where the puck is going to be? Clin Psychol Rev 26:985-999, 2006

59. Kendler KS: Explanatory models for psychiatric illness. Am J Psychiatry 165:695-702, 2008

60. Boonzaier A, Pollard A, Ftanou M, et al: The practical challenges of recruitment and retention when providing psychotherapy to advanced breast cancer patients. Support Care Cancer 18:1605-1613, 2010

\section{Affiliations}

All authors: Princess Margaret Cancer Centre; Gary Rodin, Christopher Lo, Rinat Nissim, Madeline Li, Camilla Zimmermann, and Sarah Hales, University of Toronto; Toronto, Ontario, Canada.

\section{Support}

Supported by an operating grant from the Canadian Institutes of Health Research (grant \#MOP106473 to G.R., S.H., and C.L., co-principal investigators) on the basis of a competitive scientific peer review process and indirectly through program funding from the Princess Margaret Cancer Centre, University Health Network. G.R. also is supported by the University of Toronto/University Health Network Harold and Shirley Lederman Chair in Psychosocial Oncology and Palliative Care, and C.Z. holds the Rose Family Chair in Supportive Care from the University of Toronto. The funders of the study played no role in the study design, data collection, data analysis, data interpretation, or writing of the report.

\section{Prior Presentation}

Presented at the American Society of Clinical Oncology Annual Meeting, Chicago, IL, June 2-6, 2017; the Multinational Association of Supportive Care in Cancer/International Society of Oral Oncology Annual Joint Meeting of Supportive Care in Cancer, Washington, DC, June 22-24, 2017; and the International Psycho-Oncology Society 19th World Congress of Psycho-Oncology and Psychosocial Academy, Berlin, Germany, August 14-18, 2017. 


\section{AUTHORS' DISCLOSURES OF POTENTIAL CONFLICTS OF INTEREST}

Managing Cancer and Living Meaningfully (CALM): A Randomized Controlled Trial of a Psychological Intervention for Patients With Advanced Cancer

The following represents disclosure information provided by authors of this manuscript. All relationships are considered compensated. Relationships are self-held unless noted. I = Immediate Family Member, Inst = My Institution. Relationships may not relate to the subject matter of this manuscript. For more information about ASCO's conflict of interest policy, please refer to www.asco.org/rwc or ascopubs.org/jco/site/ifc.

\section{Gary Rodin}

No relationship to disclose

\section{Christopher Lo}

No relationship to disclose

\section{Anne Rydall}

No relationship to disclose

\section{Joanna Shnall}

No relationship to disclose

\section{Carmine Malfitano}

No relationship to disclose

\section{Aubrey Chiu}

No relationship to disclose

\section{Tania Panday}

No relationship to disclose

\section{Sarah Watt}

No relationship to disclose

\section{Ekaterina An}

No relationship to disclose

Rinat Nissim

No relationship to disclose

\section{Madeline Li}

No relationship to disclose

\section{Camilla Zimmermann}

No relationship to disclose

\section{Sarah Hales}

No relationship to disclose 


\section{Acknowledgment}

We thank our research and clinical staff, students, and volunteers who contributed to the development and implementation of this trial, especially RCT therapists Valerie Heller, Cheryl Kanter, Rhonda Kibrick-Lazear, Jenny Shaheed, Fiorella Lubertacci, and Peter Fitzgerald, MD, and research staff and students Danielle Petricone-Westwood, Judy Jung, Eryn Tong, Sandra Krause, Erica Wennberg, and Caroline Neel. We also thank Haiyan Jiang, biostatistician at the PM Cancer Centre for her independent verification of the trial analyses and Paul Isaacs, $\mathrm{PhD}$, and staff at Canmark Technologies, Toronto, for data scanning, scoring, management, and export of trial data. We acknowledge the following individuals for their expertise and contributions to the trial design: Allan Donner, PhD, Mary Jane Esplen, $\mathrm{PhD}$, and Malcolm Moore, MD. Finally, we thank our study participants and their families who gave their time and effort to this project.

\section{Appendix}

\section{Treatment Integrity Scale: Managing Cancer And Living Meaningfully Evaluation of Therapist Competencies}

Therapist:

Case Number:

Case Supervision Dates:

This evaluation is completed on the basis of the case discussion in group supervision and the therapist's skills as demonstrated in those sessions. Each case presented will have one evaluation form completed. If a skill was not demonstrated in situations that demanded it, then the skill should be rated negatively. If a skill was not demonstrated because it was not applicable, the item can be left blank.

1: Needs improvement 2: Satisfactory 3: Excellent

The Therapeutic Relationship

1. __ Shows empathic understanding of patient experiences

2. __ Responds genuinely/honestly to patient thoughts and feelings

3. __ Promotes reflexive awareness (ability to consider multiple psychological responses to an event)

4. __ Acknowledges the realities of the patient's condition/situation

5. _ Maintains professional boundaries while engaging with patient experiences

6. __ Demonstrates investment/motivation/engagement in the therapeutic process

Modulating Affect

7. _ Is able to appropriately modulate the emotional state of the patient

8. __ Demonstrates comfort with emotional distress

9. Helps increase patient ability to think about/manage negative emotions/events

Shifting Frame

10._ Shifts among supportive, exploratory, and problem-solving therapeutic frames as necessary

11.__ Adjusts the content and timing of sessions on the basis of the patient's physical and psychological state

Interpretations

12.__ Offers potential explanations for the patient's pattern of distress, thoughts, or behaviors

13. Offers interpretations in the spirit of dialogue and exchange between therapist and patient

Rate the therapist's skills when addressing each domain, if applicable.

1: Needs improvement 2: Satisfactory 3: Excellent

Symptom Management and Communication With Health Care Providers

14.__ Encourages better understanding of disease

15. Encourages patient's active involvement in medical care

16. _ Promotes patient consideration of treatment options

17._ Supports communication with health care providers 


\section{Changes in Self and Relations With Close Others}

18.___ Explores patient feelings about his/her life history

19.__ Validates patient's sense of worth in light of his/her accomplishments

20.__ Acknowledges disappointments or regrets that the patient has experienced

21.__ Explores the relational changes imposed by disease

22. Explores fears and anxieties about dependency and loss of autonomy

23.___ Encourages appropriate communication and support giving/taking from close others

Spirituality or Sense of Meaning and Purpose

24.___ Explores the patient's spiritual beliefs and/or sense of meaning and purpose in life

25.__ Supports understanding of the personal meaning of their experience of suffering and dying

26. Evaluates priorities and goals in the face of advanced disease

27.__ Helps to create new meanings regarding the patient's life trajectory, goals, and suffering

Thinking of the Future, Hope, and Mortality

28. Explores patient attitudes towards the future (ie, hopes and fears about living and dying)

29.__ Allows expression of sadness and anxiety about the progression of disease

30.___ Explores feelings about death and dying

31.___ Promotes discussion of advance care planning

32. Helps to sustain realistic hope and engagement in life while acknowledging mortality

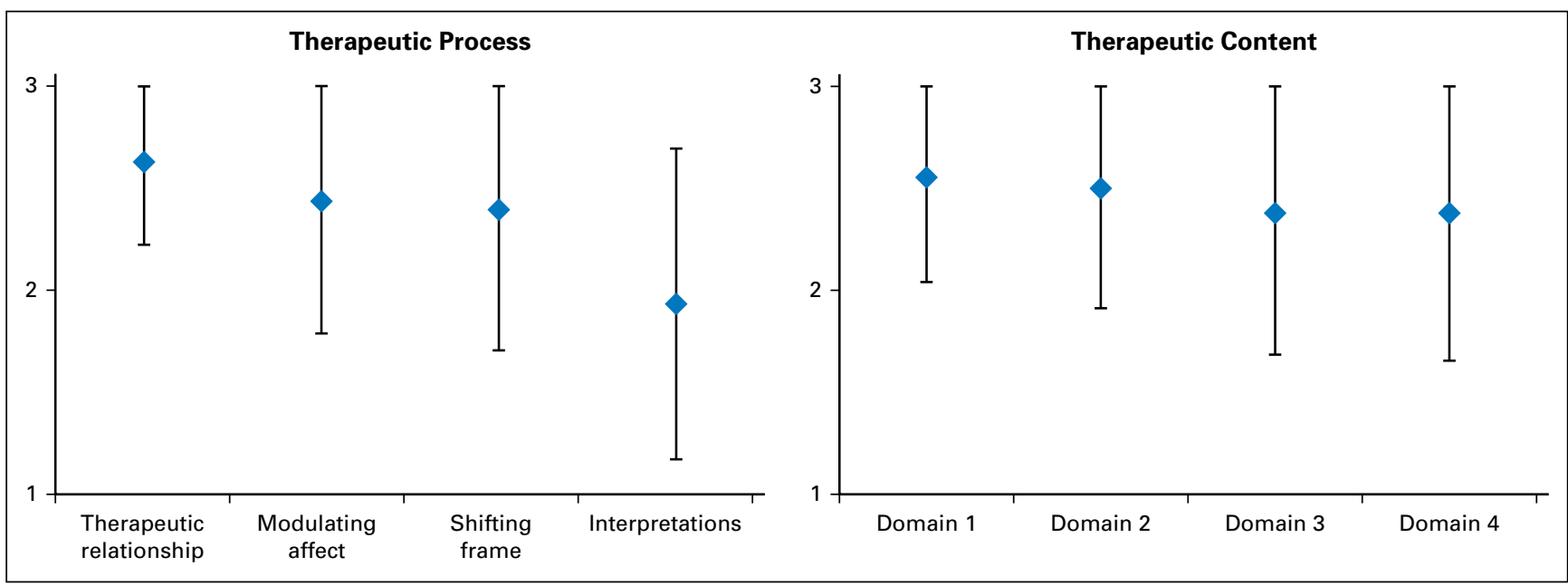

Fig A1. Treatment integrity ratings $(n=51)$. Values on the $y$-axis indicate the following ratings: $1=$ needs improvement, $2=$ satisfactory, $3=$ excellent. The therapeutic

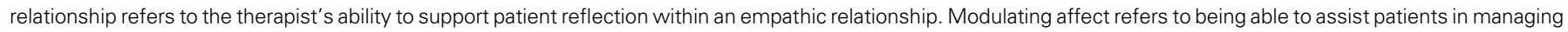

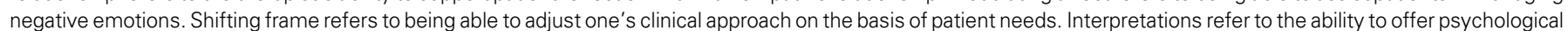

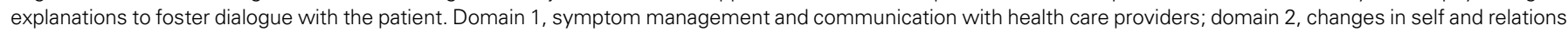

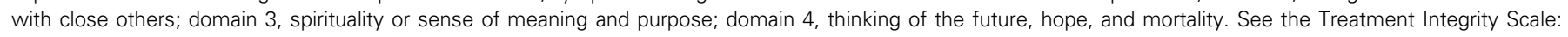
Managing Cancer And Living Meaningfully Evaluation of Therapist Competencies. 
Rodin et al

\begin{tabular}{|c|c|c|}
\hline \multirow[b]{2}{*}{ Outcome by Time } & \multicolumn{2}{|c|}{$\begin{array}{c}\text { Missing Value, } \\
\% \text { (No.) }\end{array}$} \\
\hline & UC & CALM \\
\hline No. of participants & 154 & 151 \\
\hline \multicolumn{3}{|l|}{ PHQ-9: depressive symptoms } \\
\hline t0 & $0(0)$ & $0(0)$ \\
\hline t1 & $17(26)$ & $21(32)$ \\
\hline t2 & $23(36)$ & $29(44)$ \\
\hline \multicolumn{3}{|l|}{ SCID: major depression } \\
\hline t0 & $0(0)$ & $1(2)$ \\
\hline t1 & $19(29)$ & $23(34)$ \\
\hline t2 & $26(40)$ & $30(45)$ \\
\hline \multicolumn{3}{|l|}{ GAD-7: generalized anxiety } \\
\hline to & $1(1)$ & $0(0)$ \\
\hline t1 & $21(33)$ & $25(38)$ \\
\hline t2 & $27(41)$ & $32(48)$ \\
\hline \multicolumn{3}{|l|}{ DADDS: death anxiety (total sample) } \\
\hline to & $0(0)$ & $0(0)$ \\
\hline t1 & $20(31)$ & $25(37)$ \\
\hline t2 & $25(39)$ & $32(49)$ \\
\hline \multicolumn{3}{|l|}{ FACIT-Sp-12: spiritual well-being } \\
\hline t0 & $0(0)$ & $0(0)$ \\
\hline $\mathrm{t} 1$ & $21(33)$ & $25(38)$ \\
\hline t2 & $25(38)$ & $32(48)$ \\
\hline \multicolumn{3}{|l|}{ QUAL-EC: preparation for end of life } \\
\hline to & $0(0)$ & $0(0)$ \\
\hline t1 & $21(33)$ & $25(38)$ \\
\hline t2 & 25 (39) & 32 (48) \\
\hline \multicolumn{3}{|c|}{ QUAL-EC: relationship with health care provider } \\
\hline to & $0(0)$ & $0(0)$ \\
\hline t1 & $21(33)$ & $25(38)$ \\
\hline t2 & $25(39)$ & $32(49)$ \\
\hline \multicolumn{3}{|l|}{ QUAL-EC: life completion } \\
\hline to & $0(0)$ & $0(0)$ \\
\hline t1 & $21(33)$ & $25(38)$ \\
\hline t2 & $25(39)$ & $32(48)$ \\
\hline \multicolumn{3}{|l|}{ ECR-M16: attachment insecurity } \\
\hline to & $0(0)$ & $0(0)$ \\
\hline t1 & $21(33)$ & $25(38)$ \\
\hline t2 & $25(38)$ & $33(50)$ \\
\hline \multicolumn{3}{|l|}{ CCS: couple communication } \\
\hline to & $25(39)$ & $21(31)$ \\
\hline t1 & $41(63)$ & $39(59)$ \\
\hline t2 & $47(73)$ & $44(67)$ \\
\hline \multicolumn{3}{|l|}{ PTGI: post-traumatic growth } \\
\hline to & $0(0)$ & $0(0)$ \\
\hline t1 & $22(34)$ & $26(39)$ \\
\hline t2 & 25 (39) & $32(48)$ \\
\hline \multicolumn{3}{|l|}{ DS: demoralization } \\
\hline to & $0(0)$ & $0(0)$ \\
\hline t1 & $23(35)$ & $25(38)$ \\
\hline t2 & $25(38)$ & $32(48)$ \\
\hline \multicolumn{3}{|c|}{$\begin{array}{l}\text { NOTE. CALM = UC + CALM. } \\
\text { Abbreviations: CALM, Managing Cancer And Living Meaningfully; CCS, Couple } \\
\text { Communication Scale; DADDS, Death and Dying Distress Scale; DS, De- } \\
\text { moralization Scale; ECR-M16, modified Experiences in Close Relationships } \\
\text { Scale; FACIT-Sp-12, Functional Assessment of Chronic Illness Therapy-Spiritual } \\
\text { Well-Being Scale; GAD-7, Generalized Anxiety Disorder-7; PHQ-9, Patient Health } \\
\text { Questionnaire-9; PTGI, Posttraumatic Growth Inventory; QUAL-EC, Quality of } \\
\text { Life at the End of Life Cancer Scale; SCID, Structured Clinical Interview for DSM- } \\
\text { IV-TR Disorders; t0, baseline assessment; t1, 3-month assessment (primary end } \\
\text { point); t2, 6-month assessment (trial end point); UC, usual care. }\end{array}$} \\
\hline
\end{tabular}


Table A2. Subanalyses of Participants With High and Low Death Anxiety at Baseline by Trial Arm

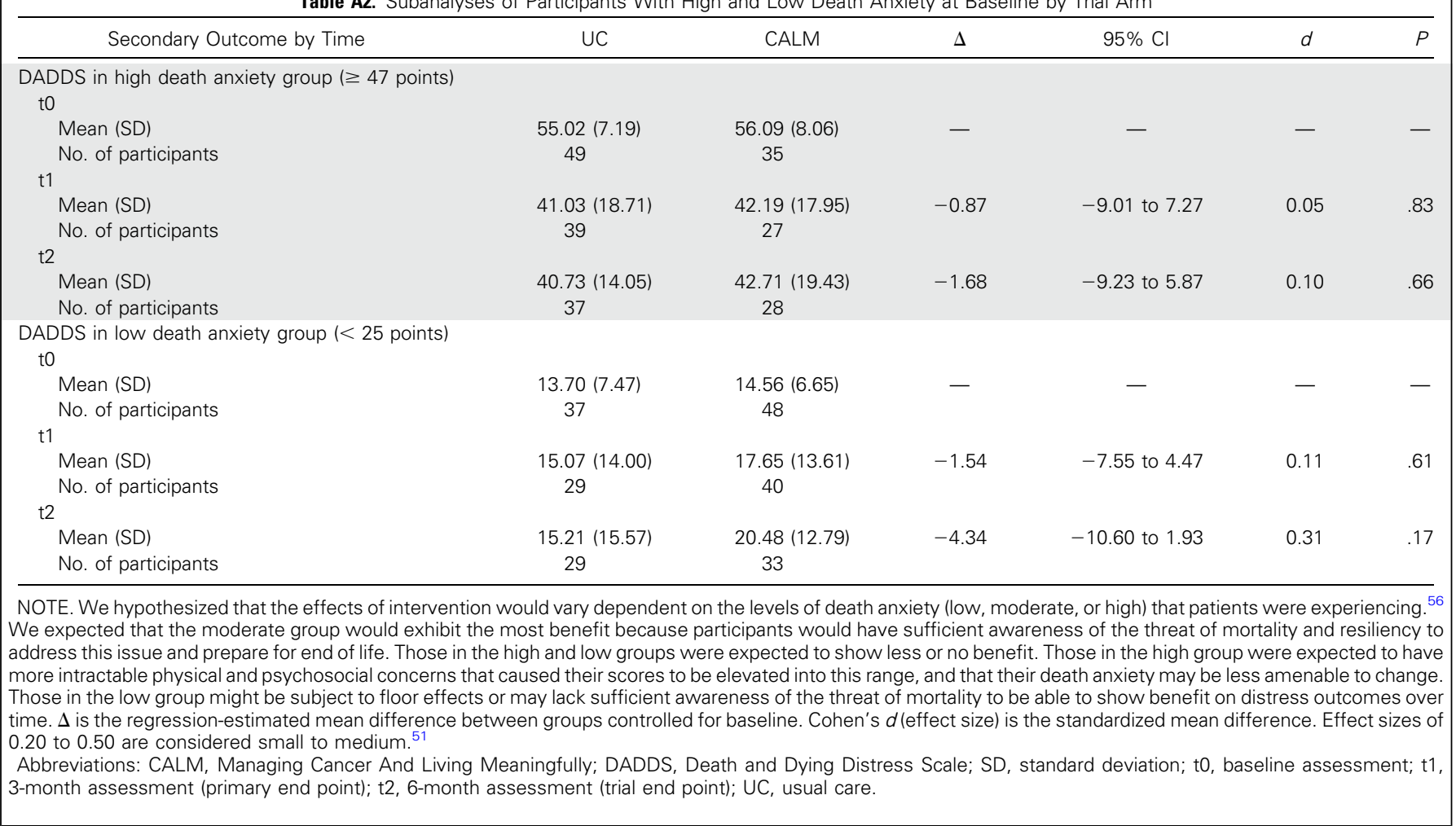

Table A3. Results From Mixed Models for the Trial Arm $\times$ Time Interactions

\begin{tabular}{lcc}
\hline \multicolumn{1}{c}{ Outcome } & $\begin{array}{c}\text { Trial Arm } \times \text { Time } \\
\text { Interaction } P\end{array}$ & $\begin{array}{c}\text { Intraclass } \\
\text { Correlation }\end{array}$ \\
\hline PHQ-9: depressive symptoms & $.048^{*}$ & 0.499 \\
GAD-7: generalized anxiety & .590 & 0.526 \\
DADDS: death anxiety & .850 & 0.656 \\
FACIT-Sp-12: spiritual well-being & .162 & 0.750 \\
QUAL-EC: preparation for end of life & $.011^{*}$ & 0.715 \\
QUAL-EC: relationship with health & .110 & 0.651 \\
$\quad$ care provider & & \\
QUAL-EC: life completion & .312 & 0.630 \\
ECR-M16: attachment insecurity & .422 & 0.654 \\
CCS: couple communication & $.004^{*}$ & 0.731 \\
PTGI: post-traumatic growth & .439 & 0.703 \\
DS: demoralization & .201 & 0.715 \\
\hline
\end{tabular}

NOTE. Mixed models were conducted by regressing each outcome on the trial $\operatorname{arm}(\mathrm{UC}, \mathrm{CALM})$, time (t0, $\mathrm{t} 1$, and $\mathrm{t} 2$ ), and their interaction, with intercepts set as random effects. Listed are results for the primary and secondary outcomes and their trial arm $\times$ time interactions. The CALM group was expected to show less distress and greater benefit over time relative to UC. There were significant effects on the PHQ-9 (reflecting a steeper decline in severity of depressive symptoms in CALM $v \cup C$ ), preparation for end of life (reflecting greater preparation for end of life in CALM $v \cup C$ ), and CCS (reflecting an increase in couple communication in UC $v$ CALM at baseline, although the two groups come to parity over time)

Abbreviations: CALM, Managing Cancer And Living Meaningfully; CCS, Couple Communication Scale; DADDS, Death and Dying Distress Scale; DS, Demoralization Scale; ECR-M16, modified Experiences in Close Relationships Scale: FACIT-Sp-12, Functional Assessment of Chronic Illness Therapy-Spiritual Well-Being Scale; GAD-7, Generalized Anxiety Disorder-7; PHQ-9, Patient Health Questionnaire-9; PTGI, Posttraumatic Growth Inventory; QUAL-EC, Quality of Life at the End of Life Cancer Scale; UC, usual care.

${ }^{*} P<.05$. 
Rodin et al

Table A4. Significant Trial Arm $\times$ Time Regression-Estimated Means

\begin{tabular}{|c|c|c|c|c|}
\hline \multirow[b]{2}{*}{ Outcome } & \multicolumn{2}{|c|}{ UC } & \multicolumn{2}{|c|}{ CALM } \\
\hline & $\bar{x}$ & $95 \% \mathrm{Cl}$ & $\bar{x}$ & $95 \% \mathrm{Cl}$ \\
\hline \multicolumn{5}{|l|}{ PHQ-9 } \\
\hline to & 7.41 & 6.67 to 8.16 & 7.45 & 6.70 to 8.20 \\
\hline t1 & 6.93 & 6.13 to 7.73 & 5.88 & 5.05 to 6.70 \\
\hline t2 & 6.72 & 5.90 to 7.54 & 5.36 & 4.50 to 6.22 \\
\hline \multicolumn{5}{|c|}{ QUAL-EC: preparation for end of life } \\
\hline t0 & 11.62 & 11.03 to 12.22 & 12.07 & 11.47 to 12.67 \\
\hline t1 & 11.80 & 11.17 to 12.43 & 13.10 & 12.46 to 13.75 \\
\hline t2 & 12.12 & 11.49 to 12.76 & 13.61 & 12.95 to 14.27 \\
\hline \multicolumn{5}{|c|}{ CCS: couple communication } \\
\hline to & 36.47 & 35.08 to 37.86 & 39.07 & 37.71 to 40.44 \\
\hline t1 & 38.28 & 36.81 to 39.75 & 38.34 & 36.89 to 39.80 \\
\hline t2 & 38.00 & 36.48 to 39.51 & 38.47 & 36.98 to 39.96 \\
\hline
\end{tabular}

NOTE. Listed are the mixed-model estimated means that explain the significant trial arm $\times$ time interactions. CALM showed a pattern of steeper decline in depressive symptoms over time and greater end-of-life preparation over time compared with UC. With regard to the CCS, the two groups seemed to differ at baseline and came to parity over time. CALM = UC + CALM.

Abbreviations: CALM, Managing Cancer And Living Meaningfully; CCS, Couple Communication Scale (higher scores reflect greater communication); PHQ-9, Patient Health Questionnaire-9 (higher scores reflect greater depressive symptom severity); QUAL-EC, Quality of Life at the End of Life Cancer Scale (higher scores reflect better preparation for end of life); t0, baseline assessment; t1, 3-month assessment (primary end point); t2, 6-month assessment (trial end point); UC, usual care. 